\title{
Erratum: The study of effect of tea polyphenols on microsatellite instability colorectal cancer and its molecular mechanism
}

\author{
Heiying Jin $\cdot$ Xuanzhong Tan $\cdot$ Xiufang Liu \\ Yijiang Ding
}

Published online: 4 December 2010

(C) Springer-Verlag 2010

\section{Erratum to: Int J Colorectal Dis}

DOI 10.1007/s00384-010-1047-x

The original version of this article unfortunately contained a mistake. Figure 1 and Figure 2 were interchanged. The correct versions are given below.

Moreover, the presentation of table 2 was missing. The correct presentation is given below.

Table 2

To demonstrate the LoVo colorectal cancer cell showed some MSI colorectal cancer feature. The LoVo cell ostomy mice model were established as we published previously (A simple colostomy implantation model for evaluating colon cancer, Int J Colorectal Dis (2009) 24:41-47) and biopsy was done on day3,week1, week2, week3 and week4. Microsatellite markers were detected and compared with day0. Some markers showed elongation or shorten, Which mean that the LoVo was the MSI colorectal cancer cell line.

The online version of the original article can be found at: http://dx.doi. org/10.1007/s00384-010-1047-x.

H. Jin $(\bowtie) \cdot X$. Tan $\cdot X$. Liu $\cdot$ Y. Ding

National Center of Colorectal Surgery, The 3rd affiliated Hospital

of Nanjing University of Traditional Chinese Medicine,

1 Jinling Road,

Jiangsu 210001, China

e-mail: jinheiying@yahoo.com.cn 
Fig. 1 Proliferation inhibition rate of LoVo and HCT-116 cells treated with different concentrations of tea polyphenol and for different amount of time
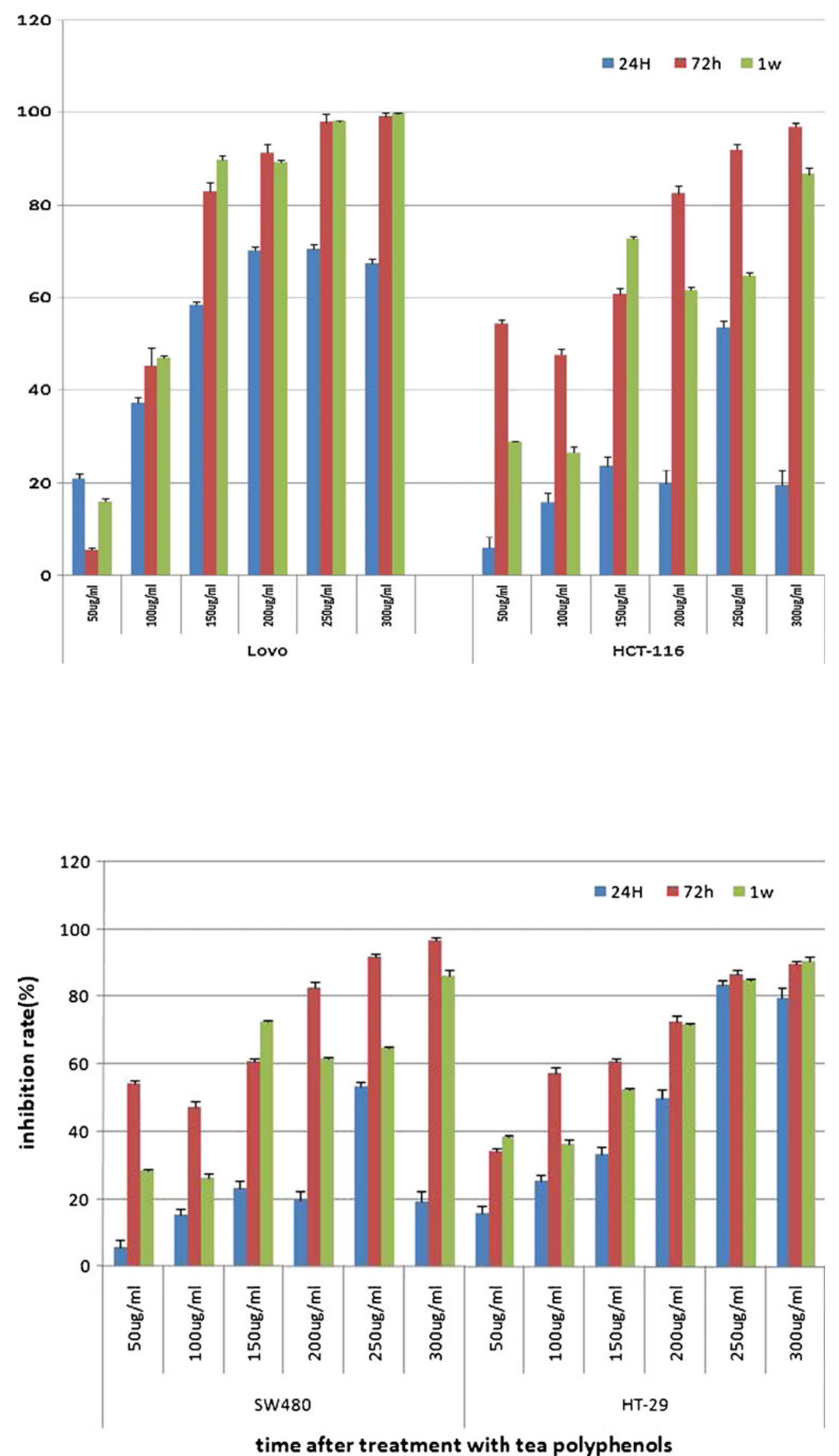

time after treatment with tea polyphenols
Fig. 2 Proliferation inhibition rate of SW480 and HT-29 cells treated with different concentrations of tea polyphenol and for different amount of time 